\title{
Parasitism strategies of the Fan-tailed Cuckoo Cacomantis flabelliformis
}

\author{
M. Guppy ${ }^{1 *}$, S. Guppy² and P. Fullagar ${ }^{3}$ \\ 'Division of Evolution, Ecology and Genetics, Research School of Biology, College of Medicine, Biology \& \\ Environment, Australian National University, Canberra ACT 0200, Australia \\ 21708 Maulbrooks Road, Moruya NSW 2537, Australia \\ ${ }^{3}$ Unit 1, 11 Joy Cummings Place, Belconnen ACT 2617, Australia \\ *Corresponding author: guppymands@bigpond.com
}

\begin{abstract}
The Fan-tailed Cuckoo Cacomantis flabelliformis inhabits thick forest, and nothing is known about how it finds the nests of its hosts, or whether it monitors the nests that it does find. We studied this cuckoo, and its hosts, for 8 breeding seasons between 2007 (August 2007-January 2008 inclusive) and 2014 (August 2014-January 2015 inclusive) on a 10-ha site in a coastal forest of south-eastern Australia, near Moruya, New South Wales. For three of these seasons, nests were monitored with cameras. The Cuckoo was recorded at the nests of only its four putative hosts at the site (White-browed Scrubwren Sericornis frontalis, Brown Thornbill Acanthiza pusilla, Superb Fairy-wren Malurus cyaneus and Variegated Fairy-wren M. lamberti). It parasitised only the nests of the White-browed Scrubwren and Brown Thornbill, but it removed either eggs or young from all other nests at which it was recorded. There was no correlation between any measure of nest activity for a host species, and parasitism of that species, and cameras at nests recorded no evidence of nest monitoring by the Cuckoo. We conclude that individual Cuckoos may be hostspecific, and that the parasitism strategy is enigmatic, but is possibly haphazard and inefficient. As a result, the Fantailed Cuckoo finds most host nests too late for successful parasitism, it spoils them to re-instigate building, and is by default a major nest-predator.
\end{abstract}

\section{Introduction}

Avian brood-parasites have evolved numerous strategies to maximise parasitism success at all stages of the process. These strategies have been exhaustively investigated in the case of the Common Cuckoo Cuculus canorus, whose habitat is often open land. The females of that species invest considerable time in finding nests by watching a nesting area (Moskat \& Honza 2000; Davies 2011), nests are rarely parasitised before the host begins laying (when there is a high risk of detection) and infrequently at the full-clutch stage (as a cuckoo is incapable of determining the age of host eggs in nests first detected at this stage: Davies \& Brooke 1988; Davies 2015). So presumably, the female monitors each nest, as it is vital that she follows the nests' progress. There is ample evidence suggesting that the female Common Cuckoo is aware of all host nests in her breeding area, before and after parasitising them (Davies \& Brooke 1988; Nakamura et al. 2005; Davies 2015). Nests in open habitat are parasitised 5-15 times more frequently than those in thicker vegetation, and the distance from a nest to the closest available cuckoo perching site is the most important determinant of parasitism (Brooke \& Davies 1987; Moksnes \& Roskaft 1987; Davies 2015). Once the nests have been found and monitored, other strategies come into play, such as those to deflect mobbing by hosts (Feeney et al. 2012), rapid egg-laying (Davies \& Brooke 1988), and mimicry of host eggs (Stoddard \& Stevens 2010). Parasitism rates vary, between host species and between populations of the same host species, from 3.3 to $67 \%$ (Davies \& Brooke 1988; Davies 2015). The best indicator of the success of a cuckoo's strategy is the number of eggs laid each season (assuming that rejection and nest-predation percentages are constant). In the Common Cuckoo, the number of eggs laid per cuckoo per season can be as high as 25 , but averages 5 (Wyllie 1975; Davies 2015).

There have been numerous studies, covering many aspects, of the bronze-cuckoos Chalcites spp. in Australasia (e.g. Briskie 2007; Langmore et al. 2008, 2011), but how any Australian cuckoo finds the nests of its hosts, and whether it monitors them, has not been addressed. This is a pertinent question with regard to the Fan-tailed Cuckoo Cacomantis flabelliformis in Australia. This species inhabits well-timbered areas with a well-developed understorey, in which only one host nest may be visible from a perch. In addition, the nests of its common hosts (the hosts vary with location: Higgins 1999) are cryptic, as is the hosts' behaviour at all stages of the nesting process. So both finding the nests and monitoring them are more difficult and onerous tasks for the Fan-tailed Cuckoo than for the Common Cuckoo.

There are data for parasitism rates by the Fan-tailed Cuckoo from two sites in Australia. In a 10-ha coastal forest site on the south-eastern coast of New South Wales (NSW), over 10 breeding seasons, the rates were 50\% (of 14 nests) for the White-browed Scrubwren Sericornis frontalis and $12 \%$ (of 50 nests) for the Brown Thornbill Acanthiza pusilla (Marchant 1992). At the same site, the rates for the Variegated Fairy-wren Malurus lamberti and Superb Fairy-wren M. cyaneus were 6\% (one of 17 nests) and $2 \%$ (one of 50 nests), respectively. Fourteen of 15 Fantailed Cuckoo eggs were laid in October or later (Marchant 1992). In the 80-ha Australian National Botanic Gardens in Canberra, Australian Capital Territory, the parasitism rate on the White-browed Scrubwren over seven breeding seasons (699 nests) was 3.6\% (R.D. Magrath pers. comm.), that on the Brown Thornbill over four seasons (88 nests) was $1.1 \%$ (Green \& Cockburn 1999), and no parasitism of the Superb Fairy-wren by the Fan-tailed 
Cuckoo has been recorded in a sample of 6000 nests (A. Cockburn pers. comm.).

The number of eggs laid per Fan-tailed Cuckoo per season in Australia is not known, because (a) the number of Cuckoos at the sites mentioned above is unknown, and (b) the territory size of this species is unknown. The data from Marchant (1992) translate to at least 1.5 Cuckoo eggs laid per breeding season per 10 ha over 10 years. The studies on the Brown Thornbill and White-browed Scrubwren were at the same site in the Australian National Botanic Gardens, and overlapped temporally, so the data can be combined, and translate to at least 0.7 Cuckoo egg laid per breeding season per 10 ha over four breeding seasons.

We have continued Marchant's study at the same site in coastal NSW, for the 2007 to 2014 breeding seasons (a breeding season runs from August in the year specified to January the following year), after a 30-year hiatus (Marchant et al. 2016), and have augmented the data using cameras at nests for the last 3 years of the study (Guppy et al. 2014, 2017). Here we analyse some of the data with the aim of answering three questions. First, how do our data on parasitism by the Fan-tailed Cuckoo compare with those of Marchant (1992) at the same site? Second, what opportunities, in terms of host activity, the number of suitable nests and the period for which these nests are available, do these hosts offer the Cuckoo for finding and parasitising nests, and is there any evidence that the Cuckoo uses these activities of potential hosts to find nests? Lastly, is there any evidence that the Cuckoo systematically monitors the state of the nests that it finds?

\section{Methods}

\section{Study site}

The study site $\left(35^{\circ} 52^{\prime} \mathrm{S}, 150^{\circ} 03^{\prime} \mathrm{E}\right)$ was 10 ha of temperate woodland ( $200 \mathrm{~m} \times 500 \mathrm{~m}, 100 \mathrm{~m}$ above sea-level), $6 \mathrm{~km}$ north-west of Moruya, NSW, and consisted of a 50-m grid of east-west and north-south paths. This type of woodland is widespread immediately inland of the coast between Ulladulla and Bermagui, NSW (Austin 1978). Our site adjoins state forest and is situated in a mixed landscape of forest and cleared grazing land, with forest as the dominant component extending for at least $20 \mathrm{~km}$ in three directions. Aerial photographs of the nearby state forest (Forestry Corporation of NSW, Southern Region, pers. comm.) show that few and only small changes to the area of forested land have occurred since 1949. This site has been described in detail previously (Guppy et al. 2014).

\section{Finding and monitoring nests}

Fieldwork comprised two people walking the grid on most (80-90\%) days during the breeding season (AugustJanuary the following year), with a daily average of $2.9 \mathrm{~h}$, from 2007 to 2014 . Walks covered $1.5-2.5 \mathrm{~km}$ and were constantly varied in direction. Nests were searched for, and individual birds associated with each nest were identified, and all of the nests were monitored until fledging or failure (usually by predation). Colour-banding was used to distinguish different breeding pairs. Birds were colourbanded either at the nest or by systematically netting the entire site.
Over the eight breeding periods, all the nests (a nest was defined as a nest that progressed to have at least one egg) of the Brown Thornbill (108), Superb Fairy-wren (121; often multiple nests for each pair) and Variegated Fairy-wren (22) were found at various stages and monitored. In the case of the White-browed Scrubwren, whose nests were more difficult to find, 17 of 20 nests were found. All pairs of White-browed Scrubwrens (which varied in number with the season between one and four, all pairs with at least one colour-banded bird) at the site were regularly observed, and the three nests that were not found were inferred from sightings of young birds being fed. It is possible with the Scrubwren (but not with the other host species), that an undetected nest could have been built, eggs laid, and then predated or abandoned after being parasitised.

A young Fan-tailed Cuckoo was never found in a nest, but successful parasitism was obvious as the young Cuckoo is large, it calls repeatedly, and the feeding regime of the hosts is unusually active. We are confident that a young Cuckoo being fed on the site by any species was never missed.

\section{Cameras and camera placement}

Cameras were used in the last three breeding seasons (2012, 2013 and 2014), as a strategy to determine the identity of nest-predators (Guppy et al. 2017). The cameras (HC500 Hyperfire Semi-Covert IR; Reconyx Inc, Wisconsin, USA) were digital, with a passive infrared motion detector, and a night-time infrared illuminator. They were mounted on a metal stake, or strapped to a tree, and positioned (irrespective of the species) $100-150 \mathrm{~cm}$ from nests that were $0-3 \mathrm{~m}$ above ground. The cameras provide a wide-angle view and the frame encompasses at least $20 \mathrm{~cm}$ (usually at least $50 \mathrm{~cm}$ ) in all directions from the nest. One camera was placed at each nest and set on high sensitivity to take 10 pictures (1 per second) for each trigger. The camera was placed at the nest as soon as it was found, and left there until the birds fledged or until the nest failed. It was armed at all times and would trigger in response to the host birds; therefore there was no doubt that a Fan-tailed Cuckoo, a much larger bird, would cause a trigger. There was a delay of $c .7$ seconds between successive triggers. Each SD memory card held $\sim 10000$ pictures, and the cameras and nests were checked every 1-3 days (Guppy et al. 2014, 2017). The cameras were deployed at various proportions of the nests of the Brown Thornbill $(6,11$ and 10 breeding pairs for the 2012, 2013 and 2014 breeding seasons respectively), Superb Fairy-wren (8, 9 and 7 pairs), White-browed Scrubwren (3, 3 and 2 pairs) and Variegated Fairy-wren (2, 2 and 1 pairs) at the building, egg or young stage (Table 1). All the Brown Thornbill nests were monitored with a camera each year, but the coverage was not as complete (33-100\%: Table 1) for the two fairy-wren species. White-browed Scrubwren nests were difficult to find $(0-100 \%$ were monitored with a camera) and the main reason for not deploying a camera there was that the nest had been found at the late feeding stage. If a Cuckoo was recorded interacting with a nest in any way that we have defined (including nests that we did not find, but which produced a fledgling Cuckoo), this nest was considered to be 'found' by a Cuckoo. 
Table 1. Camera monitoring of nests of putative host species of the Fan-tailed Cuckoo, Moruya, New South Wales, breeding seasons from 2012 to 2014: total number of nests, percentage of nests monitored by a camera, and stage of each nest when the camera was deployed. Stage: $B=$ building, $E=$ eggs, $Y=$ young. Successful nests were those where young fledged

\begin{tabular}{|c|c|c|c|}
\hline Breeding season & $\begin{array}{l}\text { Total number of nests } \\
\text { (\&\% successful) }\end{array}$ & $\begin{array}{c}\text { Nests monitored by a camera } \\
(\%)\end{array}$ & $\begin{array}{c}\text { Stage (\& } \% \text { nests at that stage) at } \\
\text { which camera was deployed }\end{array}$ \\
\hline \multicolumn{4}{|l|}{ Brown Thornbill } \\
\hline 2012 & $6(29)$ & 100 & $\mathrm{~B}(17), \mathrm{E}(17), \mathrm{Y}(66)$ \\
\hline 2013 & $14(58)$ & 100 & B (79), E (21), Y (0) \\
\hline 2014 & $16(6.3)$ & 100 & B (94), E (0), Y (6) \\
\hline \multicolumn{4}{|c|}{ Superb Fairy-wren } \\
\hline 2012 & $13(58)$ & 69 & B (0), E (78), Y (22) \\
\hline 2013 & $17(54)$ & 65 & B (27), E (46), Y (27) \\
\hline 2014 & $10(50)$ & 100 & B (30), E (70), Y (0) \\
\hline \multicolumn{4}{|c|}{ White-browed Scrubwren } \\
\hline 2012 & $1(100)$ & 0 & \\
\hline 2013 & $4(75)$ & 25 & $B(0), E(100), Y(0)$ \\
\hline 2014 & $3(0)$ & 100 & $B(100), E(0), Y(0)$ \\
\hline \multicolumn{4}{|c|}{ Variegated Fairy-wren } \\
\hline 2012 & $2(50)$ & 50 & $B(0), E(100), Y(0)$ \\
\hline 2013 & $3(84)$ & 33 & $B(100), E(0), Y(0)$ \\
\hline 2014 & $2(0)$ & 100 & $\mathrm{~B}(0), \mathrm{E}(0), \mathrm{Y}(100)$ \\
\hline
\end{tabular}

\section{Nest stages}

For detailed analysis, we used three nest stages: active, building and 1-2 egg. The data from only the three camera seasons were used, and from only the two species that were parasitised during the study (Brown Thornbill and White-browed Scrubwren). Both of these host species have a clutch-size of three (any other clutch-size is rare) at this site. Active nests comprise first building activity to last young fledged or loss of the nest. For a more precise measure of opportunity for parasitism, we separated out (a) building nests (first building activity to first egg laid), as we reasoned that these offer the best opportunity for the Fan-tailed Cuckoo to initially find a host nest because of the host activity involved, and (b) 1-2-egg nests (nests containing either one or two eggs), as these nests represent the most suitable stage for successful parasitism.

\section{Calculation of number of nest-days}

If a nest was discovered during the building stage, the state of that nest, every day, was known through monitoring. If a nest was found with eggs or young, the history of the nest was determined by back-calculating, using a combination of hatching or fledging dates, the estimated age of the young birds, and known (for this site) periods for fledging, incubation, laying and building. The number of nest-days for any stage is the sum of the number of nests at that stage for each day of the active nest period. The data are accurate $( \pm 2$ days) for the Brown Thornbill. There is more uncertainty for the White-browed Scrubwren as it is not possible to see inside these nests; it is difficult to feel inside the nests without disturbing them and their surroundings, and we have found that there are significant risks of abandonment if the nests are disturbed. Data for this species often had to be inferred from the behaviour of the adults, so some of the timing ascribed to the Scrubwren nests is accurate to \pm 5 days. There is also an inherent uncertainty when building activity is part of the calculation (active nests and building nests), as the birds do not build every day, and a finished nest is sometimes left empty for up to a week before laying. A nest categorised as a 'building nest' may not have building activity associated with it every day.

\section{Results}

\section{Presence of a Fan-tailed Cuckoo at the site}

During the three breeding seasons when nests were being monitored with cameras (2012, 2013 and 2014), at least one Fan-tailed Cuckoo was heard and/or seen at the site every month (July-January inclusive) except for July and August in 2012 and July in 2014.

\section{Parasitism}

Over the eight breeding seasons, there were four cases of parasitism by the Fan-tailed Cuckoo of the White-browed Scrubwren (one in 2011, two in 2013 and one in 2014), one of the Brown Thornbill (2011), and none of either the Variegated Fairy-wren or Superb Fairy-wren. This equates to 0.63 Cuckoo egg laid per season per 10 ha, and a parasitism rate of $20 \%$ for the White-browed Scrubwren and $0.9 \%$ for the Brown Thornbill. In addition, (a) a Fantailed Cuckoo egg was laid in a Brown Thornbill nest (2009), which was subsequently abandoned and another nest built, and (b) the nest of a pair of Brown Thornbills was 'spoiled' (see the concept of 'farming', which is addressed in the Discussion) by a Fan-tailed Cuckoo (2012), with the host pair subsequently building another nest (off the study site) that was not found. This pair of Brown Thornbills subsequently appeared at the site with a young dependent 
Fan-tailed Cuckoo. One Cuckoo egg was laid on c. 25 September, and all the others were laid after 7 October.

\section{Interaction of the Fan-tailed Cuckoo with host nests, breeding seasons 2012-2014}

During the three camera seasons (2012-2014), cameras were placed at 169 nests of 18 species of birds, and 62 interactions were recorded, comprising 16 species of predator (Guppy et al. 2017). The Fan-tailed Cuckoo was seen only at nests of its four putative hosts, and there was only one instance of another species of cuckoo being recorded (i.e. a bronze-cuckoo removed young birds from the nest of a Brown Gerygone Gerygone mouki). During this period, the Fan-tailed Cuckoo parasitised $21 \%$ of the nests that it 'found'. A Fan-tailed Cuckoo removed eggs or young from three Brown Thornbill nests (50\% of nests) in 2012, no Cuckoo was seen at a Brown Thornbill nest in 2013, and a Cuckoo removed young from one Brown Thornbill nest in 2014 (Table 2). A Cuckoo was not seen at a White-browed Scrubwren nest in 2012 or 2013, but removed eggs from two Scrubwren nests, and young from another in 2014. A Cuckoo was not seen at a Superb Fairy-wren nest in 2012, but removed young from a Superb Fairy-wren nest in 2013 and eggs from two nests in 2014. A Cuckoo removed eggs from a Variegated Fairy-wren nest in 2012, but was not seen at a nest of that species in 2013 or 2014. Two of these cuckoo-nest interactions (at Whitebrowed Scrubwren nests) occurred on c. 20 September, and the rest took place after 7 October.

\section{Nest stages for the Brown Thornbill and White- browed Scrubwren}

1. Active stage (nest active in terms of building through to fledging). The average number of active nest-days per season for the two species combined was $533 \pm$ standard deviation $237(n=3)$. Of these, the Brown Thornbill accounted for an average of $84 \%$ and the White-browed Scrubwren $16 \%$. The maximum number of active nests on any one day was $6-12$, depending on the season.

2. Building stage (Figure 1). The average number of building nest-days per season for the two species combined was $173 \pm 72(n=3)$. Of these, the Brown Thornbill accounted for an average of $85 \%$ and the White-browed Scrubwren 15\%. The maximum number of nests being built on any one day was 3-8, depending on the season.

3. 1-2-egg stage (Figure 2). The average number of 1-2-egg nest-days per season for the two species combined was $75 \pm 41(n=3)$. Of these, the Brown Thornbill accounted for an average of $87 \%$ and the White-browed Scrubwren 13\%. The maximum number of 1-2-egg nests on any one day was $2-4$, depending on the season.

\section{Discussion}

The most common parasitism by the Fan-tailed Cuckoo in the current study was of the White-browed Scrubwren, followed by the Brown Thornbill. Neither of the fairy-wrens was parasitised. Most of the Cuckoo activity occurred after
Table 2. Activity of Fan-tailed Cuckoos at nests of putative host species, Moruya, New South Wales, breeding seasons from 2012 to 2014. Number of photographic records of each activity are shown in the table.

\begin{tabular}{|c|c|c|c|}
\hline \multirow[t]{2}{*}{ Activity } & \multicolumn{3}{|c|}{ Breeding season } \\
\hline & 2012 & 2013 & 2014 \\
\hline \multicolumn{4}{|l|}{ Brown Thornbill } \\
\hline Removing eggs & 1 & & \\
\hline Removing young & 2 & & 1 \\
\hline \multicolumn{4}{|c|}{ Superb Fairy-wren } \\
\hline Removing eggs & & & 2 \\
\hline Removing young & & 1 & \\
\hline \multicolumn{4}{|c|}{ White-browed Scrubwren } \\
\hline Removing eggs & & & 2 \\
\hline Removing young & & & 1 \\
\hline \multicolumn{4}{|c|}{ Variegated Fairy-wren } \\
\hline Removing eggs & 1 & & \\
\hline Removing young & & & \\
\hline
\end{tabular}

September, and 0.63 Cuckoo egg was laid per season per 10 ha. The data from the current study are thus qualitatively consistent with those of Marchant (1992), but a quantitative comparison is not possible because of the low numbers in both studies. In addition, neither of these studies provides any indication of either parasitism or eggs laid per Cuckoo, as neither the number of Cuckoos at the site, nor the area being covered by each Cuckoo, was known.

The second question raised in the Introduction concerned the opportunities for nest detection (and therefore subsequent parasitism) presented by the potential hosts at the site. We used the number of active nest-days as a coarse measure of opportunity. For a particular nest, this value is affected by the lifetime of the nest, which in turn is affected by an interacting combination of building times, laying intervals, incubation and fledging times. These parameters are not strikingly different between the two host species. However, the total number of active nest-days is also related to (a) the number of breeding pairs of potential hosts (6-11 for Brown Thornbill and 2-3 for White-browed Scrubwren for the 2012-2014 breeding seasons), through the number of nests built, (b) success rates, which affect the lifetime of a nest, and (c) the propensity of the species to rebuild after losing a nest. The result of the interaction of all these factors is that the opportunities for detection presented by the Brown Thornbill were five-fold greater than those presented by the White-browed Scrubwren. The effects of success rates are demonstrated by the data from 2013 and 2014; the number of nests built in these two breeding seasons by the Brown Thornbill was similar, but the success rates were markedly different, resulting in a $34 \%$ decrease in active nest-days in 2014 compared with 2013. So do cuckoos cue into some factor associated with this coarse measure of active nests to find the nests of the hosts? If the two host species in this study are equally preferred by the Fan-tailed Cuckoo, the answer is no, as the parasitism rate was highest for the species (Whitebrowed Scrubwren) that had the fewest active nest-days.

We reasoned that building activity might be a more obvious and specific clue for a cuckoo, and as such its 
2012

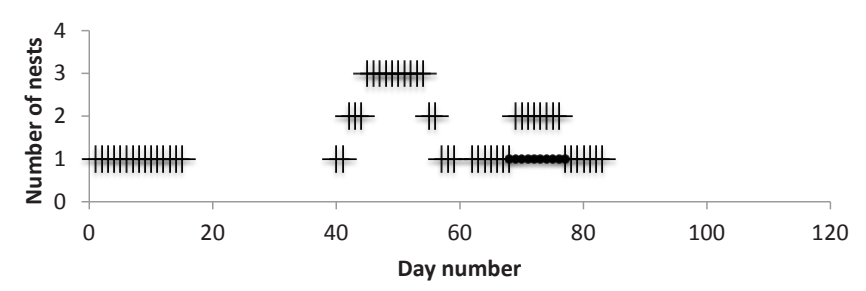

2013

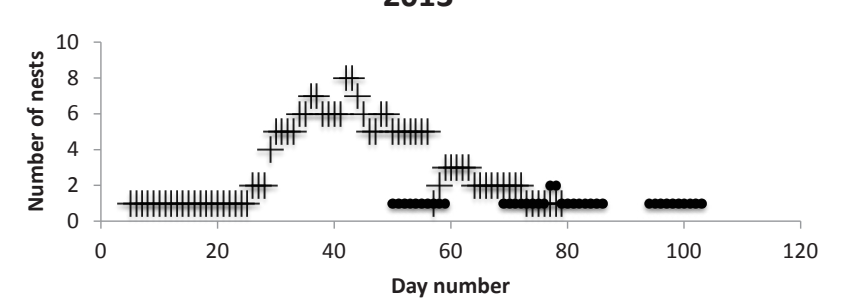

2014

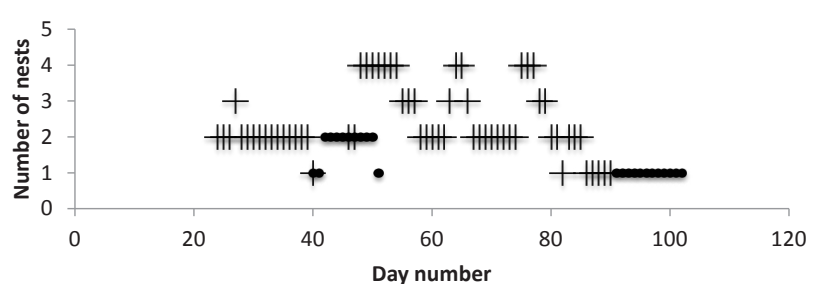

Figure 1. Number of nests at the building stage each day of the active nest period in the breeding seasons from 2012 to 2014, Moruya, New South Wales, for the Brown Thornbill (crosses) and White-browed Scrubwren (black spots). The date on the $\mathrm{x}$-axis has been converted to Day number, in which Day $1=15$ July, Day $18=1$ August, Day $49=1$ September, Day $79=1$ October and Day $100=$ 22 October. Note that these figures do not portray the full complexity of the rolling situation. For example, the data describing number of nests $=1$ for 2012 actually comprise five different nests over the 83-day period, which can be spread over the entire site (see Figure 3 ). The equivalent number for 2013 is four, and for 2014 is three.

detection could be a mechanism by which a cuckoo could locate a nest (feeding activity is also obvious, but occurs too late for parasitism). Building nest-days account for between 12 and $17 \%$ of the life of the nest, depending on the host species. In addition, at the level of the community of each host species, multiple pairs, nests that overlap in time, and varying success rates are involved, so the situation becomes complex, and the higher the number of pairs the more complex it becomes. For example, using a combination of the Brown Thornbill and Superb Fairywren data, over a season at this site, up to 14 pairs and a rolling total of 24 nests can be present, many of them being rebuildings by the Superb Fairy-wren after either failed or successful nests (only $\sim 20 \%$ of Brown Thornbill nests are rebuilt after loss or success at this site: MG \& SG unpubl. data). As with active nest-days, however, the number of building nest-days is inversely proportional to the number of nests parasitised, for the White-browed Scrubwren and the Brown Thornbill (Figure 1). Thus, again assuming that both host species are equally preferred, the Fan-

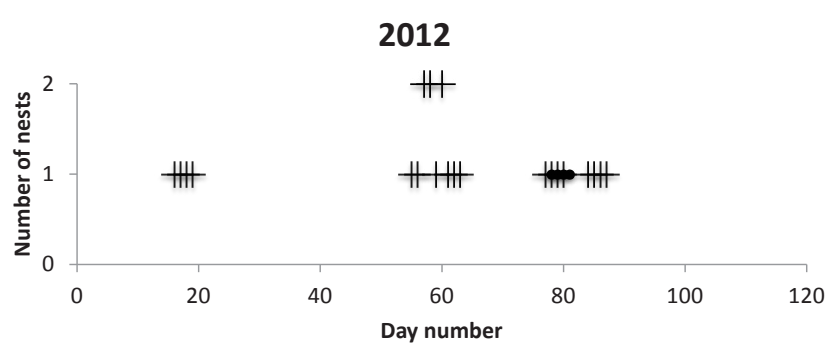

2013
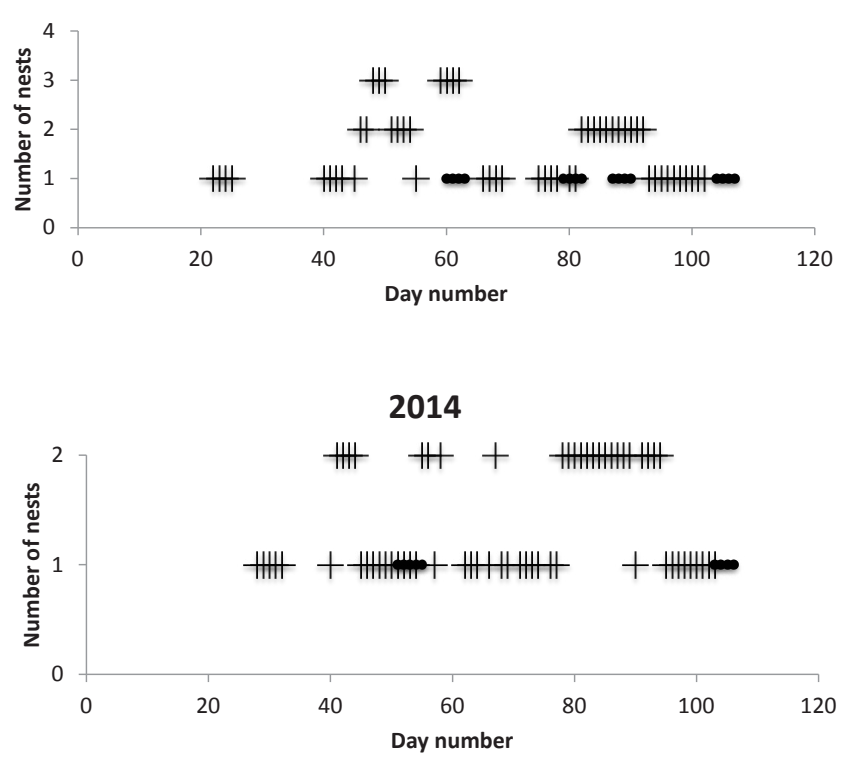

Figure 2. Number of nests at the 1-2 egg-stage each day of the active nest period, for the Brown Thornbill (crosses) and White-browed Scrubwren (black spots) for the breeding seasons from 2012 to 2014, Moruya, New South Wales. The date on the $x$-axis has been converted to Day number, in which Day $1=15$ July, Day $18=1$ August, Day $49=1$ September, Day $79=1$ October and Day $100=$ 22 October.

tailed Cuckoo seems not to be cueing in on the number of building nest-days to find suitable nests.

Another possibility is that the nests are found purely by chance. The evidence for this is that over the 3 years when cameras were used we recorded 11 instances at host nests in which either eggs (always from full clutches) or young were removed (i.e. the nest was spoiled: Table 2), from nests that were found too late and were not suitable for parasitism. These data are consistent with random searching, as at least $70 \%$ of the life of a nest comprises stages after successful parasitism is possible. However, random searching should have resulted in more spoiling of nests of Brown Thornbills and Superb Fairy-wrens than of White-browed Scrubwrens, as there were more nests of the former two species. But this was not the case.

An alternative explanation invokes host-specificity for female Fan-tailed Cuckoos, which are receptive only to an as-yet-unknown behaviour exhibited by that particular host species. There is evidence for female host-specificity in the Common Cuckoo. The females of the different gentes of that species mimic the eggs of one particular host species and are fairly to totally consistent in their choice of host species (Nakamura et al. 2005; Antonov et al. 2010; Davies 2015). There is some evidence for this specificity in our data on the Fan-tailed Cuckoo. There were three 


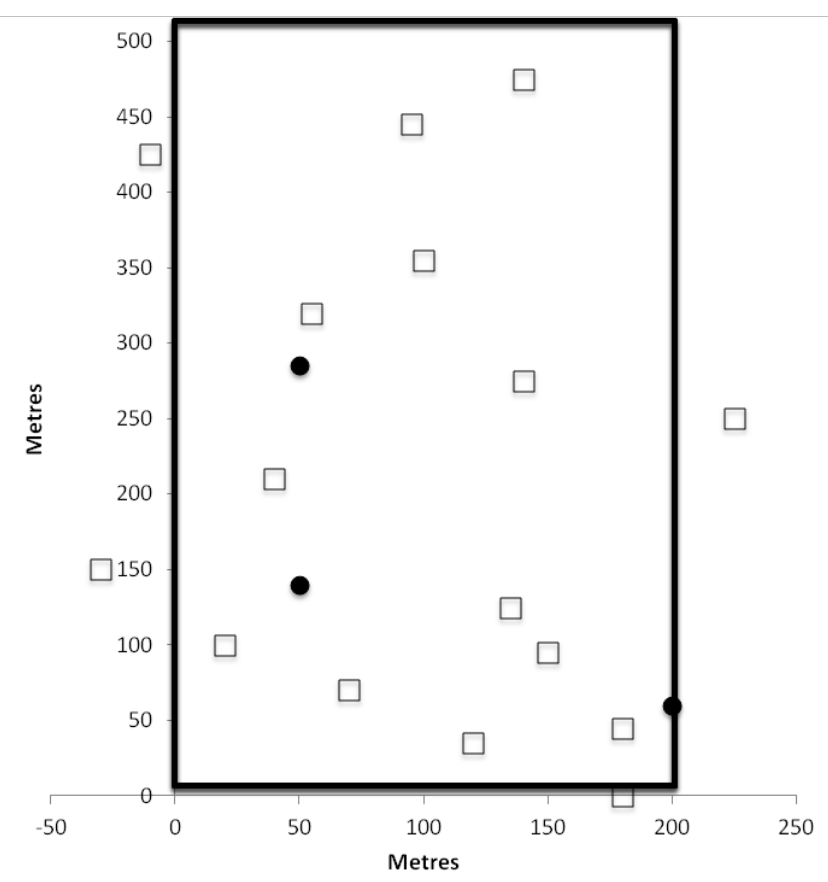

Figure 3. Brown Thornbill (open squares) and Whitebrowed Scrubwren (closed circles) nests within (and just outside) the study site (200 m $\times 500 \mathrm{~m}$; outlined in bold) in the 2014 breeding season, Moruya, New South Wales.

cases of spoiling (eggs or young removed from the nest but no parasitism of the nest) of Brown Thornbill nests in 2012 (half of the nests), but none in 2013 and only one in 2014; yet in both 2013 and 2014 there were more Brown Thornbill nests than in 2012. The parasitism of the Whitebrowed Scrubwrens occurred in 2013 and 2014, and three nests of this species were spoiled in 2014. These data are minimal, but are consistent with there being a Brown Thornbill-specific female Fan-tailed Cuckoo at the site in 2012, and a White-browed Scrubwren-specific female at the site in 2013 and 2014. However, the data are equivocal, as a Variegated Fairy-wren nest was spoiled (eggs removed) in 2012, and nests of three species were spoiled in 2014 (Table 2).

If the behaviour of the Common Cuckoo is any guide, the 1-2-egg stage (i.e. when there is at least one egg in the nest, but before the full clutch is laid) would be the time of choice for parasitism of the two host species. If this is the case, the Fan-tailed Cuckoo at the study site has only $\sim 10 \%$ of the life of a nest in which to successfully parasitise it, which equates to 4 days for both the Brown Thornbill and White-browed Scrubwren (both of which lay at 48-h intervals). As with building nest-days, the rolling situation can be very complex. For example, on $45.3 \pm 21.2$ days $(n=3)$ (out of the 100-day breeding season for the Brown Thornbill) there is at least one nest suitable for parasitism, but (a) there is usually only a maximum of two nests available on any one day out of a rolling total of 6-11 active nests (Figure 2), (b) the location of these suitable nests is changing every 4 days (because of 48-h laying intervals), and (c) these nests are spread over 10 ha of relatively dense forest (Figure 3 ). There are only 7 days over the three seasons when there are three Brown Thornbill nests at the 1-2-egg stage. In contrast, for the White-browed Scrubwren there are only $9.7 \pm 6$ days when there is a nest suitable for parasitism (out of the 64-day breeding season), and over the three seasons there is never more than one suitable White-browed Scrubwren nest available on any one day. These data show the challenges faced by a cuckoo to find a nest at the right stage for parasitism. And once again, the number of 2-egg nest-days is inversely proportional to the number of nests parasitised for the White-browed Scrubwren and the Brown Thornbill (Figure 2).

This brings us to the last question posed in the Introduction. We investigated whether Fan-tailed Cuckoos systematically monitor the nests of the host species at this site: we put cameras at as many nests as possible, as early as possible, looking for evidence of actual parasitism, or nest investigation/monitoring (monitoring in this case means physical investigation of a nest, which would be detected by a camera). No parasitism was recorded via this method. Nonetheless, there were three cases of parasitism by Fan-tailed Cuckoos during the 3 years of the study when cameras were deployed, all at White-browed Scrubwren nests. In only one of these cases did we find the nest, and that was only when the hosts started feeding the young Cuckoo in the nest (the other cases of parasitism were detected by finding the hosts feeding a young fledged Cuckoo at the site). Despite having cameras at 36 Brown Thornbill nests, 34 fairy-wren nests, and four White-browed Scrubwren nests over three breeding seasons, in 2012-2014, we have no evidence of a nest being investigated or monitored by a Fan-tailed Cuckoo. We recorded one instance of a Cuckoo looking inside an empty Brown Thornbill nest, but no eggs were ever laid in this nest. Apart from this one occasion, every time (11 records) that a Cuckoo was recorded at a nest, the nest contained either the full clutch of eggs, or young, and the Cuckoo removed all the eggs or young and did not parasitise the nest. However, in one case of parasitism of a White-browed Scrubwren nest, we found the first nest of the pair of Scrubwrens, recorded on camera the removal of the eggs by a Cuckoo (although it was not possible to determine the fate of the eggs), and subsequently ( 63 days later) found this pair of Scrubwrens feeding a young mobile Cuckoo. The same sequence of events happened with parasitism of a Brown Thornbill nest in 2012 (see Results). The fact that these two host pairs were parasitised after eggs were removed from the original nests suggests that the nests were deliberately spoiled, and that the Thornbill/ Scrubwren hosts were monitored by the Cuckoo after the nests were spoiled. However, again, the evidence is equivocal: there are three cases in Table 2 of spoiling of White-browed Scrubwren nests, and in only one case (see above) was the pair subsequently parasitised.

This strategy of spoiling of host nests during late incubation or the nestling stage (i.e. when the nests are no longer suitable for parasitism) has received relatively little attention, but removal of eggs and nestlings from host nests by the Shining Bronze-Cuckoo Chalcites lucidus has been observed (Chalk 1950; Briskie 2007; Guppy et al. 2017). It is thought that the purpose of this strategy is to instigate re-nesting by the host and ensure a ready supply of host nests that are at a suitable stage for parasitism ('farming': Hoover \& Robinson 2007), and it may also allow a cuckoo to synchronise its laying with that of the host, because relaying by the host typically occurs at a predictable time following nest destruction (Arcese et al. 1996). 
At our study site we have recorded numerous instances of a Fan-tailed Cuckoo at a nest. These interactions were recorded only at the nests of the four species that are its putative hosts, at which we had 64 cameras over the three breeding seasons (2012-2014). In contrast, during these three seasons a Cuckoo was not seen at the 105 nests of other species that were monitored with a camera. Only once was a Cuckoo seen at a nest without spoiling it; this nest was empty and never reached the egg stage. Each of the other 11 visits was when the nests contained either the full clutch or nestlings. We conclude that at this site the Fan-tailed Cuckoo visits the nests of only its putative hosts, and does not monitor (at least as detectable on camera) these nests.

There are three conclusions that can be drawn from these data. Firstly, the parasitism rates by the Fantailed Cuckoo on the Brown Thornbill and White-browed Scrubwren are not correlated with the number of speciesspecific active, building, or 1-2-egg nest-days. Secondly, the Cuckoo is not systematically monitoring the nests of any of its four hosts at this site, at least in a way that we could detect. Thirdly, the Cuckoo visits the nests of only its putative hosts, and all recorded visits by the Cuckoo to what we have defined as a nest were related to spoiling. So we would simplify the definition of farming (see Hoover \& Robinson 2007 above) for the Fan-tailed Cuckoo; the purpose is to instigate re-nesting by the host, which may be the only way this cuckoo can ensure access to host nests that are at a suitable stage for parasitism. This last point is important, as the Fan-tailed Cuckoo, through its spoiling behaviour, is the second most frequent nestpredator at the site (Guppy et al. 2017). Although no parasitism of the two fairy-wren species was recorded, a Cuckoo removed eggs from one Variegated Fairy-wren nest, and eggs or young from Superb Fairy-wren nests (Table 2). The removal of young birds from nests certainly constitutes nest spoiling as the young were not eaten, and were still alive when dropped outside the nests (as recorded on camera). In fact, we doubt if a Cuckoo would be physically able to eat the young that were removed from the nest. None of these conclusions are weakened by the possibility that there is more than one female Cuckoo at the site, or that a Cuckoo that we recorded was actually working a much larger territory than that represented by our survey site. Whatever is happening at this site would be representative of the surrounding area, regardless of the number of Cuckoos involved. And it may be more complex than simple territories, as Nakamura et al. (2005) showed that the female Common Cuckoo has distinct breeding and feeding areas.

We offer two parasitism strategies that are consistent with the data for the Fan-tailed Cuckoo. In the first, the female Cuckoo locks on to an actual bird (of a specific species if she is host-specific) and simply follows it from a high perch. It will either lead her to its nest (if it is building, brooding or feeding young), in which case, if the nest is at a suitable stage, the Cuckoo parasitises it immediately. Or, the cuckoo either monitors the nest until it is at the 1-2-egg stage (at a distance beyond triggering a camera) and then parasitises it, or spoils it if she has found it too late. If the host does not lead the cuckoo to a nest over a day, it is not building, brooding or feeding young, so the Cuckoo moves on to find another individual. In the second strategy, the female haphazardly finds nests (she can be host-specific or not), usually finds them too late for parasitism, spoils them, and then follows that pair of hosts and closely monitors the replacement nest

\section{Acknowledgements}

We were helped immeasurably by a group of dedicated bird banders led by Anthony Overs and operating under banding licence numbers 2195 and 2857. We also thank the Australian Bird and Bat Banding Scheme for the supply of numbered metal bands. Nick Davies and an anonymous reviewer provided comments that improved the manuscript.

\section{References}

Antonov, A., Stokke, B.G., Vikan, J.R., Fossoy, F., Ranke, P.S., Roskaft, E., Moksnes, A., Moller, A.P. \& Shykoff, J.A. (2010). Egg phenotype differentiation in sympatric cuckoo Cuculus canorus gentes. Journal of Evolutionary Biology 23, 1170-1182.

Arcese, P., Smith, N.M. \& Hatch, M.I. (1996). Nest predation by cowbirds and its consequences for passerine demography. Proceedings of the National Academy of Sciences of the United States of America 93, 4608-4611.

Austin, M.P. (1978). Vegetation. In: Gunn, R.H. (Ed.). Land Use on the South Coast of New South Wales, Volume 2: Biophysical Background Studies, pp. 44-66. CSIRO, Melbourne.

Briskie, J.V. (2007). Direct observations of shining cuckoos (Chrysococcyx lucidus) parasitising and depredating grey warbler (Gerygone igata) nests. Notornis 54, 15-19.

Brooke, M. de L. \& Davies, N.B. (1987). Recent changes in host usage by cuckoos Cuculus canorus in Britain. Journal of Animal Ecology 56, 873-883.

Chalk, A.S. (1950). Strange behaviour of a cuckoo. Emu 49, 219.

Davies, N.B. (2011). Cuckoo adaptations: Trickery and tuning. Journal of Zoology 284, 1-14.

Davies, N.B. (2015). Cuckoo: Cheating by Nature. Bloomsbury, London.

Davies, N.B. \& Brooke, M. de L. (1988). Cuckoos versus reed warblers: Adaptations and counteradaptations. Animal Behaviour 36, 262-284.

Feeney, W.E., Welbergen, J.A. \& Langmore, N.E. (2012). The frontline of avian brood parasite-host coevolution. Animal Behaviour 84, 3-12.

Green, D.J. \& Cockburn, A. (1999). Life history and demography of an uncooperative Australian passerine, the brown thornbill. Australian Journal of Zoology 47, 633-649.

Guppy, M., Guppy, S., Marchant, R., Priddel, D., Carlile, N. \& Fullagar, P. (2017). Nest predation of woodland birds in southeast Australia: Importance of unexpected predators. Emu 117, 92-96.

Guppy, M., Guppy, S., Priddel, D. \& Fullagar, P. (2014). Nest predators of a woodland community in south-east Australia. Australian Zoologist 37, 105-116.

Higgins, P.J. (Ed.) (1999). Handbook of Australian, New Zealand \& Antarctic Birds, Volume 4: Parrots to Dollarbird. Oxford University Press, Melbourne.

Hoover, J.P. \& Robinson, S.K. (2007). Retaliatory mafia behavior by a parasitic cowbird favors host acceptance of parasitic eggs. Proceedings of the National Academy of Sciences of the United States of America 104, 4479-4483.

Langmore, N.E., Maurer, G., Adcock, G.J. \& Kilner, R.M. (2008). Socially acquired host-specific mimicry and the evolution of host races in Horsfield's bronze-cuckoo Chalcites basalis. Evolution 62, 1689-1699.

Langmore, N.E., Stevens, M., Maurer, G., Heinsohn, R., Hall, M.L., Peters, A. \& Kilner, R.M. (2011). Visual mimicry of host nestlings by cuckoos. Proceedings of the Royal Society of London B: Biological Sciences 278, 2455-2463. 
Marchant, R., Guppy, S. \& Guppy, M. (2016). The influence of ENSO and rainfall on the numbers of breeding pairs in a woodland bird community from south-eastern Australia. Emu 116, 254-261.

Marchant, S. (1992). A Bird Observatory at Moruya, NSW 1975-84. Eurobodalla Natural History Society Occasional Publication No. 1, Moruya, NSW.

Moskat, C. \& Honza, M. (2000). Effect of nest and nest site characteristics on the risk of cuckoo Cuculus canorus parasitism in the great reed warbler Acrocephalus arundinaceus. Ecogeography 23, 335-341.

Moksnes, A. \& Roskaft, E. (1987). Cuckoo host interactions in Norwegian mountain areas. Ornis Scandinavica 18, 168-172.
Nakamura, H., Miyazawa, Y. \& Kashiwagi, K. (2005). Behaviour of radio-tracked Common Cuckoo females during the breeding season in Japan. Ornithological Science 4, 31-41.

Stoddard, M.C. \& Stevens, M. (2010). Pattern mimicry of host eggs by the common cuckoo, as seen through a bird's eye. Proceedings of the Royal Society London B: Biological Sciences 277, 1387-1393.

Wyllie, I. (1975). Study of cuckoos and reed warblers. British Birds 68, 369-378.

Received 29 October 2016, accepted 2 March 2017, published online 31 May 2017 